\title{
White Matter Vulnerability to Ischemic Injury Increases with Age Because of Enhanced Excitotoxicity
}

\author{
Selva Baltan, ${ }^{1}$ Elaine F. Besancon, ${ }^{2}$ Brianna Mbow, ${ }^{1}$ ZuCheng Ye, ${ }^{1}$ Margaret A. Hamner, ${ }^{1}$ and Bruce R. Ransom ${ }^{1}$ \\ ${ }^{1}$ Department of Neurology, Harborview Medical Center, Seattle, Washington 98104, and ${ }^{2}$ School of Medicine, Harvard University, Boston, Massachusetts \\ 02115
}

\begin{abstract}
Stroke incidence increases with age and this has been attributed to vascular factors. We show here that CNS white matter (WM) is intrinsically more vulnerable to ischemic injury in older animals and that the mechanisms of WM injury change as a function of age. The mouse optic nerve was used to study WM function. WM function in older animals (12 months) was not protected from ischemic injury by removal of extracellular $\mathrm{Ca}^{2+}$ or by blockade of reverse $\mathrm{Na}^{+} / \mathrm{Ca}^{2+}$ exchange, as is the case with young adults. Ischemic WM injury in older mice is predominately mediated by glutamate release and activation of AMPA/kainate-type glutamate receptors. Glutamate release, attributable to reverse glutamate transport, occurs earlier and is more robust in older mice that show greater expression of the glutamate transporter. The observation that WM vulnerability to ischemic injury is age dependent has possible implications for the pathogenesis of other age-related CNS conditions.
\end{abstract}

Key words: glutamate; glutamate transporter; axon; NMDA receptors; stroke; AMPA/kainate receptors

\section{Introduction}

Aging is one of the most significant risk factors for stroke. Although it is assumed that age-related cardiovascular complications, including atherosclerosis and cardiac dysfunction, account for this association, aging could result in changes such that CNS tissue itself has an altered susceptibility to ischemic injury. This important question has not been definitively tested, although a few studies have suggested that age-related changes might play a role in ischemic injury (Ay et al., 2005; Schaller, 2007).

Axonal pathways, that is, white matter (WM), are greatly expanded in humans compared with rodents $(\sim 50$ and $\sim 15 \%$ of brain volume, respectively) (Zhang and Sejnowski, 2000). It is now clear that white matter is injured in most strokes and contributes importantly to clinical deficits. Virtually every drug candidate that selectively conferred protection to neurons in experimental stroke studies has failed in clinical trials (Del Zoppo, 1995, 1998; Dirnagl, 2006; O’Collins et al., 2006), and we suggest that failure to protect WM is one of the primary reasons that needs to be explored. Mechanisms underlying ischemic WM injury have proved to be unique and unexpectedly complex (Wrathall et al., 1992; Agrawal and Fehlings, 1997; Fern and Ransom, 1997; McDonald et al., 1998; Sanchez-Gomez and Matute, 1999; Follett et al., 2000; Tekkök and Goldberg, 2001; Stys, 2004; Tekkök et al., 2007). This is, in part, attributable to the participation of at least two distinct but converging injury mechanisms:

Received Sept. 19, 2007; revised Dec. 20, 2007; accepted Dec. 27, 2007.

This work was supported by American Heart Association National Scientist Development Grant (S.B.), United Spinal Grant (B.R.R., S.B.), Sidney Multiple Sclerosis Research Grant (B.R.R.), and National Institutes of Health Grant NS015589 (B.R.R.). We gratefully acknowledge insightful comments on this manuscript by Sean Murphy.

Correspondence should be addressed to Dr. Selva Baltan, Department of Neurology, Box 359665, Harborview Medical Center, Room R\&T 413, 325 Ninth Avenue, Seattle, WA 98104. E-mail: selva@u.washington.edu. D0I:10.1523/JNEUROSCI.5137-07.2008

Copyright $\odot 2008$ Society for Neuroscience $\quad$ 0270-6474/08/281479-11\$15.00/0 ionic rearrangements caused by energy depletion, followed by excessive glutamate accumulation and subsequent overactivation of AMPA and kainate receptors (Stys, 2004; Tekkök et al., 2007). Unfortunately, all of the experimental work on ischemic WM injury has been conducted in young adult animals. Aging is known to affect WM, from altering the relationship between myelin and axons to changing the relative densities of cellular constituents (Peters and Sethares, 2002; Sandell and Peters, 2002; Hinman et al., 2006; Hinman and Abraham, 2007). Ischemic strokes occur primarily in the elderly, and so it is essential to understand whether advanced age affects the susceptibility of WM to ischemic injury and/or the mechanisms of injury. To address these issues, we characterized ischemiainduced injury using the optic nerve from 1-, 6-, 12-, 18-, and 24-month-old mice. The optic nerve, a purely myelinated CNS WM tract (Foster et al., 1982), is one of three models that have been extensively used to study ischemic injury (Agrawal and Fehlings, 1996; Tekkök and Goldberg, 2001). The optic nerve is sensitive to the aging process (Cavallotti et al., 2002, 2003) and offers several advantages in studying the mechanisms of WM injury including the capacity to quantitatively assess ischemic injury using electrophysiological and immunohistochemical methods.

Our results indicated that the same ischemic insult was much more damaging to WM from older animals compared with young adults. Furthermore, in older animals the mechanism of injury was different and depended predominately on glutamatemediated excitotoxicity. The enhanced role of excitotoxicity was probably attributable in part to the increased expression of GLT1 with aging, a change that was specific to WM. A detailed understanding of WM ischemic injury in age-appropriate populations is of central importance to meet the challenge of developing ef- 
fective stroke therapy. Some of these results were previously presented in abstract form (Baltan, 2007).

\section{Materials and Methods}

Preparation of optic nerves, recording techniques, and oxygen and glucose deprivation. As previously described (Tekkök et al., 2007), mouse optic nerves (MONs) were obtained from anesthetized adult male Swiss Webster (SW) mice of $1,6,12,18$, or 24 months of age. The oldest nerves were only $\sim 18 \%$ larger in diameter than the 1 -month-old nerves. The mean life span of this mouse strain is $\sim 24-26$ months (Charles River, Wilmington, MA). Optic nerves were gently freed from their dural sheaths and placed in an interface perfusion chamber (Medical Systems, Greenvale, NY). Both nerves from each animal were used simultaneously on identical setups to reduce animal numbers. Nerves were superfused with artificial CSF (ACSF) containing the following (in mmol/L): $124 \mathrm{NaCl}$, 3.0 KCl, 2.0 $\mathrm{CaCl}_{2}, 2.0 \mathrm{MgCl}_{2}, 1.25 \mathrm{NaH}_{2} \mathrm{PO}_{4}, 23 \mathrm{NaHCO}_{3}$, and 10 glucose. The chamber was continuously aerated by a humidified gas mixture of $95 \% \mathrm{O}_{2} / 5 \% \mathrm{CO}_{2}$. $\mathrm{O}_{2}$ was supplied entirely by this gas mixture (see below). All experiments were performed at $37^{\circ} \mathrm{C}$ except for some experiments on 24 -month-old MONs which were performed at $31^{\circ} \mathrm{C}$ to investigate the effects of temperature on ischemic injury.

Suction electrodes back-filled with ACSF were used for stimulation (Isostim 520; WPI, Sarasota, FL) and recording the compound action potential (CAP). The recording electrode was connected to an Axoclamp $2 \mathrm{~A}$ amplifier, and the signal was amplified 50 times, filtered at $30 \mathrm{kHz}$, and acquired at $20-30 \mathrm{kHz}$. Stimulus pulse (30 $\mu$ s duration) strength was adjusted to evoke the maximum CAP possible, and then increased another $25 \%$ for supramaximal stimulation. The MONs were allowed to equilibrate for at least $15 \mathrm{~min}$ in the chamber in normal ACSF (containing $2 \mathrm{mM} \mathrm{Ca}^{2+}$ ) before experiments. During experiments, the supramaximal CAP was elicited every $30 \mathrm{~s}$.

Oxygen and glucose deprivation (OGD) was induced by switching to glucose-free ACSF (replaced with equimolar sucrose to maintain osmolarity) and a gas mixture containing $95 \% \mathrm{~N}_{2} / 5 \% \mathrm{CO}_{2}$. To ensure that no oxygen was inadvertently delivered by the superfusate, ACSF was always bubbled with $95 \% \mathrm{~N}_{2} / 5 \% \mathrm{CO}_{2}$ (Ransom and Philbin, 1992). The OGD was applied for 30,45 , or 60 min to determine the effects on axonal conduction and recovery. After OGD, control ACSF and $\mathrm{O}_{2}$ were restored and CAPs were recorded for up to $6 \mathrm{~h}$.

$\mathrm{A} \mathrm{Ca}^{2+}$-free ACSF was used in some experiments and contained 200 $\mu \mathrm{M}$ EGTA and $4 \mathrm{~mm} \mathrm{Mg}^{2+}$ (to maintain constant divalent cation concentration). Control experiments indicated that CAPs in every age group remained essentially unchanged in this solution (with normal glucose and oxygen) for at least $90 \mathrm{~min}$. In some experiments, $\mathrm{Ca}^{2+}$ entry through the reversal of $\mathrm{Na}^{+}-\mathrm{Ca}^{2+}$ exchanger (NCX) was blocked by using 2-[2-[4(4-nitrobenzyloxy)phenyl]ethyl]isothiourea mesylate (KB-R 7943 mesylate) (10 $\mu \mathrm{M}$; Tocris, Ellisville, MO; dissolved in DMSO as $10 \mathrm{~mm}$ stock).

To explore the role of AMPA/kainate receptors in OGD-induced axon function loss in MONs, the antagonist 1,2,3,4-tetrahydro-6-nitro-2,3dioxo-benzo[f] quinoxaline-7-sulfonamide (NBQX) (30 $\mu \mathrm{M}$; Tocris; dissolved in DMSO as $30 \mathrm{~mm}$ stock, care being taken to prevent light exposure) was applied in the bath. To assess the contribution of NMDA receptors to ischemic injury 7-chlorokynurenic acid (7-CKA) (50 $\mu \mathrm{M}$; Tocris; glycine binding site blocker, dissolved in DMSO as $50 \mathrm{~mm}$ stock) or DL-amino-5-phosphonopentanoic acid (DL-AP5) (200 $\mu \mathrm{M}$; Tocris; potent selective NMDA receptor blocker, dissolved in $100 \mathrm{~mm} \mathrm{NaOH}$ as 100 mM stock) was used.

The role of $\mathrm{Na}^{+}$-dependent glutamate transport as a potential source of glutamate release was tested using the transport blockers DL-threo- $\beta$ benzyloxyaspartate (DL-TBOA) (200 $\mu \mathrm{M}$; Tocris; dissolved as $100 \mathrm{~mm}$ stock in $100 \mathrm{~mm} \mathrm{NaOH}$ ) or dihydrokainic acid (DHKA) (200 $\mu \mathrm{M}$; Tocris; dissolved as $100 \mathrm{~mm}$ stock in $100 \mathrm{~mm} \mathrm{NaOH}$ ). All chemicals were applied starting $30 \mathrm{~min}$ before, during, and $30 \mathrm{~min}$ after OGD. None of the chemicals used altered the CAP area under control conditions.

Immunohistochemistry. Immunohistochemical assessment of WM structures was performed in perfusion-fixed MONs. After transcardial $\operatorname{ACSF}\left(\right.$ at $4^{\circ} \mathrm{C}$ ), the perfusion medium was switched to a fixative composed of $4 \%$ paraformaldehyde in PBS. The animals were kept for at least
$1 \mathrm{~h}$ at $4^{\circ} \mathrm{C}$. Then, optic nerves were dissected out and kept in fixative overnight at $4^{\circ} \mathrm{C}$. Cryoprotection was in 10,20, and 30\% sucrose solutions for $4,6-8$, and $16-18 \mathrm{~h}$, respectively, before sectioning. Ten- to $30-\mu \mathrm{m}$-thick sections from each MON were cut on a cryotome (Leica, Bellevue, WA) and mounted on Superfrost slides (Fisher Scientific, Pittsburgh, PA) for immunohistochemical analysis. The sections were blocked and permeabilized in 5-40\% normal goat serum (Sigma, St. Louis, MO) and $0.3 \%$ Triton X-100 (Sigma) for $60 \mathrm{~min}$ at room temperature. All primary antibodies were prepared in the same solution. Astrocytes were identified with a polyclonal antibody to glial fibrillary acidic protein (GFAP) (DiaSorin, Stillwater, MN), or monoclonal GFAP, Cy3 conjugated (Sigma). NR1 (Chemicon, Temecula, CA) for NMDA receptors, GLT1 (a generous gift from Dr. J. Rothstein, Baltimore, MD) for glutamate transporter 1, and Sytox (Invitrogen, Carlsbad, CA) for nuclei detection were used. For each condition, immunolabeling was examined and quantified in three to six animals, and in two to three adjacent sections (10 $\mu \mathrm{m}$ thick) from each animal. Primary antibodies were used at a dilution of 1:15 for polyclonal GFAP (prediluted six times), 1:1000 for monoclonal GFAP, 1:500 for NR1, 1:200 for GLT1, and 1:25,000 for Sytox. Sections were incubated in primary antibodies together overnight at $4^{\circ} \mathrm{C}$. After a thorough wash in PBS, the tissue was exposed to a secondary antibody, one by one for each primary, prepared in $2 \%$ normal goat serum for $2 \mathrm{~h}$ at room temperature. Donkey anti-rabbit Cy5 (Jackson ImmunoResearch, West Grove, PA) at a dilution of 1:100 was used. Sections were double or triple labeled to colocalize structures of interest.

Confocal microscopy and GLT1 pixel intensity measurements. The expression of NR1, GFAP, Sytox, or GLT1 was imaged using an Olympus (Center Valley, PA) FV1000 upright laser-scanning confocal microscope. Sections were scanned with an argon and $\mathrm{He}-\mathrm{Ne}$ lasers for $\mathrm{Cy} 3 / 543$, for Cy5/633, and for Cy2/488 fluorescence. Two to three adjacent sections from each MON were imaged for a total of two or three areas of interest per MON. A total of 30 optical sections of $1 \mu \mathrm{m}$ thickness at $1024 \times 1024$ pixel size were collected in the $z$-axis from a single microscopic field using the $60 \times$ (PlanApo, oil immersion; numerical aperture, 1.42; Olympus) objective lens under fixed gain, laser power, pinhole, and PMT settings. To compare and quantify immunohistochemical staining properties, sections obtained from each age group were processed together. Optimal settings were determined in 1-month-old tissue. Images were acquired with Olympus Fluoview imaging software in sequential mode using multiple channels simultaneously. $Z$-stacks were projected into a single plane image before analysis and assessment of pixel intensity or colocalization.

Glutamate measurements. Glutamate release from MON into the superfusate under normoxic and ischemic conditions was measured using HPLC (Ye et al., 2003; Tekkök et al., 2007). Experiments were designed to monitor glutamate release simultaneously from a pair of MONs, 1 or 12 months of age. Briefly, amino acids were precolumn derivatized with $o$-phthaldialdehyde (Sigma), separated, and measured using standard techniques. Samples of extracellular perfusion fluid were collected continuously such that every vial contained 2 min of superfusate, and glutamate content was measured in every other vial (i.e., every $4 \mathrm{~min}$ ). Collected samples were centrifuged at 16,000 $\times g$ for 3 min and supernatants transferred for HPLC analysis. Glutamate measurements, normalized to baseline glutamate release (i.e., the average for $15 \mathrm{~min}$ under control conditions immediately before OGD or TBOA treatment), were made from MONs treated identically with those studied electrophysiologically, and the results were plotted against time. The rate and release pattern of glutamate was monitored for $30 \mathrm{~min}$ before OGD (60 min) and was continued for at least $30 \mathrm{~min}$ after the end of OGD. Glutamate levels were corrected to protein content of MONs before comparison.

Immunoblotting. Optic nerves and hippocampi were dissected from 1and 12-month-old male SW mice. Tissues were homogenized in ice-cold RIPA buffer (50 mu Tris- $\mathrm{HCl}$, pH 8.0, $150 \mathrm{~mm} \mathrm{NaCl}, 1 \% \mathrm{NP}-40,0.5 \%$ sodium deoxycholate, $0.1 \%$ SDS) containing $10 \%$ protease inhibitor mixture. After $30 \mathrm{~min}$ incubation on ice, the samples were centrifuged at room temperature for $2 \mathrm{~min}$ at 13,200 rpm. Protein determinations of the supernatants were made using the DC Protein Assay (Bio-Rad, Hercules, CA) with bovine serum albumin (BSA) as standard. The samples were then diluted in a Laemmli buffer (62.5 mM Tris-HCl, pH 6.8, 10\% glycerol, $2 \%$ SDS, $0.1 \%$ bromophenol blue, $6 \% \beta$-mercaptoethanol), 
a
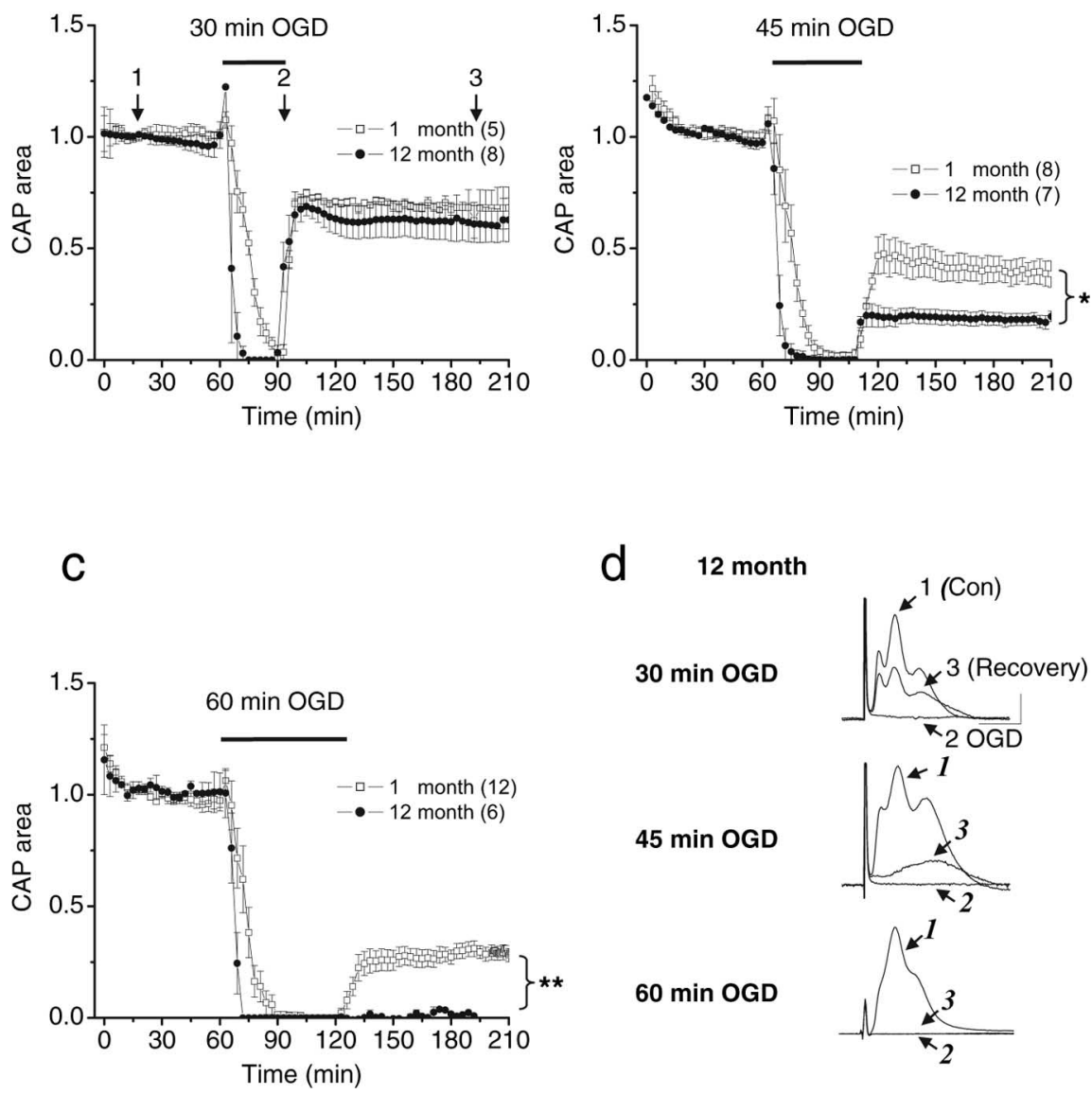

d

$30 \mathrm{~min}$ OGD

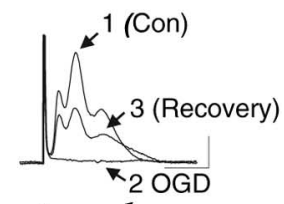

$45 \min O G D$

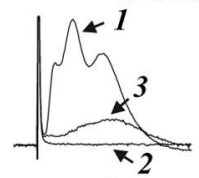

$60 \mathrm{~min} O G D$

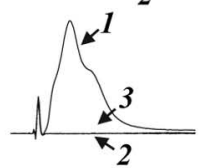

Figure 1. Recovery of WM function depends on age and the duration of $0 G D$. The CAP area recovery after 30,45 , or 60 min of OGD was either similar $(\boldsymbol{a})$ reduced $(\boldsymbol{b})$, or completely abolished (c) in 12-month-old MONs compared with 1-month-old MONs. Each point represents the CAP area averaged from the number of separate experiments indicated in parentheses. CAPs were elicited every $30 \mathrm{~s}$ by supramaximal stimulation. For simplifying the illustrations, the CAP area and SEMs are plotted every $3 \mathrm{~min}$. $\boldsymbol{d}$, Aging increased the vulnerability of axons to $\mathrm{OGD}$, but the evoked CAPs preserved their characteristic forms. Representative traces show CAPs and the extent of recovery after 30, 45, or 60 min OGD in 12-month-old animals. Traces represent CAPs before OGD (1), at the end of OGD (2), and after recovery (3) as indicated in the plot $(\boldsymbol{a}) .{ }^{*} p=0.0185,{ }^{* *} p=0.0011$, Student's $t$ test. Calibration: $2 \mathrm{mV}, 1 \mathrm{~ms}$.

boiled for $10 \mathrm{~min}$, and stored at $-20^{\circ} \mathrm{C}$. Samples containing equal amounts of protein $(30 \mu \mathrm{g})$ were loaded and separated by gel electrophoresis using a $10 \%$ acrylamide gel and transferred for $2 \mathrm{~h}$ at room temperature onto a polyvinylidene fluoride membrane $(0.45 \mu \mathrm{m}$; Millipore, Temecula, CA). The membranes were then blocked overnight at $4^{\circ} \mathrm{C}$ in $5 \%$ nonfat dry milk, $1 \%$ BSA, $1 \%$ fetal bovine serum (FBS) in Tris-buffered saline containing $0.1 \%$ Tween 20 (TBS-T). Membranes were then incubated for $2 \mathrm{~h}$ at room temperature with primary antibodies against the glutamate transporter GLT1 (1:500;), GFAP (1:1000; Chemicon), or $\beta$-actin (1:500; Sigma) in TBS-T containing $1 \%$ nonfat dry milk, $1 \%$ BSA, and $\%$ FBS. After thorough washing in TBS-T, the membranes were incubated for $2 \mathrm{~h}$ at room temperature with horseradish peroxidase-conjugated anti-rabbit IgG (1:1000; Sigma) or antimouse IgG (1:1000; Sigma) in the same solution used for the primary antibodies, washed again in TBS-T, and developed using luminol (Santa Cruz Biotechnology, Santa Cruz, CA) to reveal immunolabeled bands. The films were scanned with a Hewlett Packard 2820 scanner, and optical densities of the bands were analyzed using MetaMorph analysis software. The GLT1 and GFAP expression levels were normalized to $\beta$-actin as a control for equal loading. A single film was used to analyze optical densities from both optic nerve and hippocampi samples. However, protein abundance is different in WM and gray matter (GM), and, for presenta- tion purposes, two films of different exposure times were used to show representative optic nerve and hippocampus data for GLT1. N indicates number of animals for immunoblotting.

Data analysis. Optic nerve function was monitored quantitatively as the area under the supramaximal CAP. The CAP area is proportional to the total number of excited axons and represents a convenient and reliable means of monitoring optic nerve axon function (Cummins et al., 1979; Stys et al., 1991). Irreversible injury was measured by determining residual CAP area, normalized to control CAP area, 3-4 $\mathrm{h}$ after the conclusion of OGD. Original data were normalized by setting the mean of initial baseline values (measured over $15 \mathrm{~min}$ ) to a value of 1.0. Results from several nerves were pooled, averaged, and plotted against time. All data are presented as mean and SE ( \pm SEM). In time course plots, SE bars are only shown every 3 min to make the illustration less cluttered. Statistical significance was determined by unpaired two tailed Student's $t$ test (see Figs. 1, 3, 4, 5, 8e,f, 9; supplemental Fig. 2, available at www.jneurosci.org as supplemental material), one-way (supplemental Figs. 1, 2, available at www.jneurosci.org as supplemental material), or two-way ANOVA (see Figs. 6, 7, 8d). ANOVA tests were followed by Bonferroni's post hoc test (Prism 4; GraphPad, San Diego, CA).

\section{Results \\ Older WM is intrinsically more vulnerable to oxygen-glucose deprivation}

The effects of OGD on axon excitability and WM integrity were determined in optic nerves obtained from 1-, 6-, 12-, 18-, and 24-month-old mice. Under control conditions, axon function (quantified as the area under the CAP evoked by supramaximal stimulation) remained stable over many hours at $37^{\circ} \mathrm{C}$ in all age groups. After $1 \mathrm{~h}$ of stable control CAPs, OGD was imposed and resulted in a progressive loss of the CAP area. The rate at which the CAP area fell changed in an age-dependent manner (Fig. 1a; supplemental Fig. 1, available at www.jneurosci.org as supplemental material). The rate of CAP area loss increased with age until 18 months of age, and then declined in older animals (supplemental Fig. $1 a, b$, available at www.jneurosci.org as supplemental material).

The extent of irreversible injury detected after a period of OGD varied as a function of OGD duration and age (Figs. 1, 2). For example, after 30,45 , or $60 \mathrm{~min}$ of OGD in 1-month-old MONs, the CAP area recovered to $68.7 \pm 3.2 \%(n=5), 46.4 \pm$ $9.6 \%(n=8)$, or $21.3 \pm 3.7 \%(n=12)$ of control, respectively. The amount of irreversible injury caused by OGD (durations, $>30 \mathrm{~min}$ ) was greater in animals 12 months of age and older, compared with younger animals (Figs. $1 b, c, 2$ ). For example, the CAP area recovery in 12-month-old MONs after 30, 45, and 60 $\min$ OGD was $58.6 \pm 5.5 \%(n=8 ; p=0.2046), 17.7 \pm 2.9 \%(n=$ $7 ; p=0.0185)$, and $0.0 \pm 1.0 \%(n=6 ; p=0.0011)$ of control, respectively; the $p$ values given are in comparison with CAP recoveries after the same OGD exposures in 1-month-old MONs. 

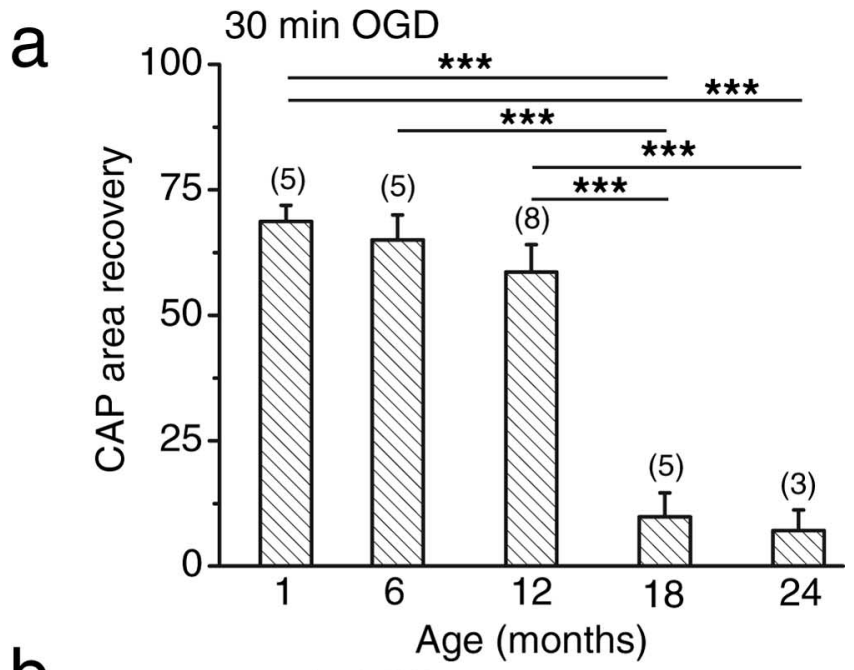

b

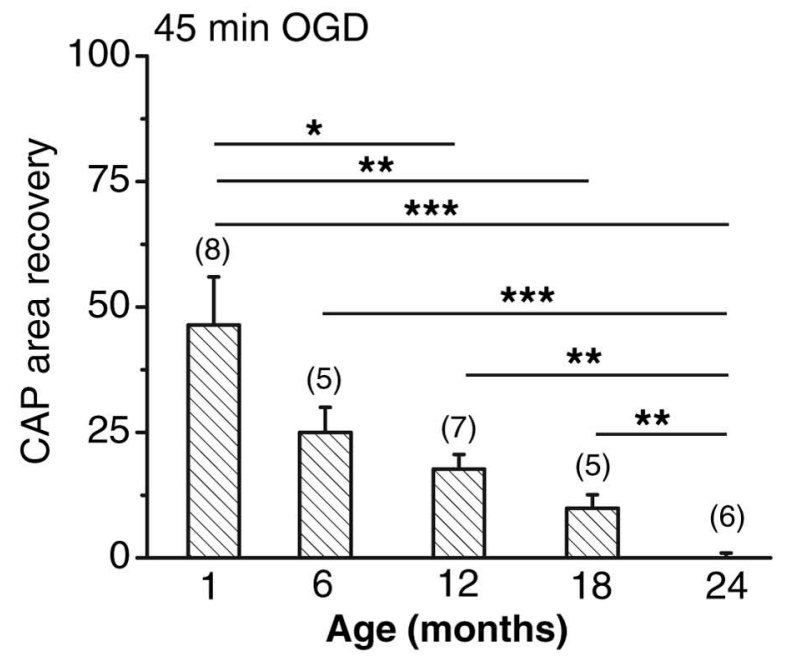

C

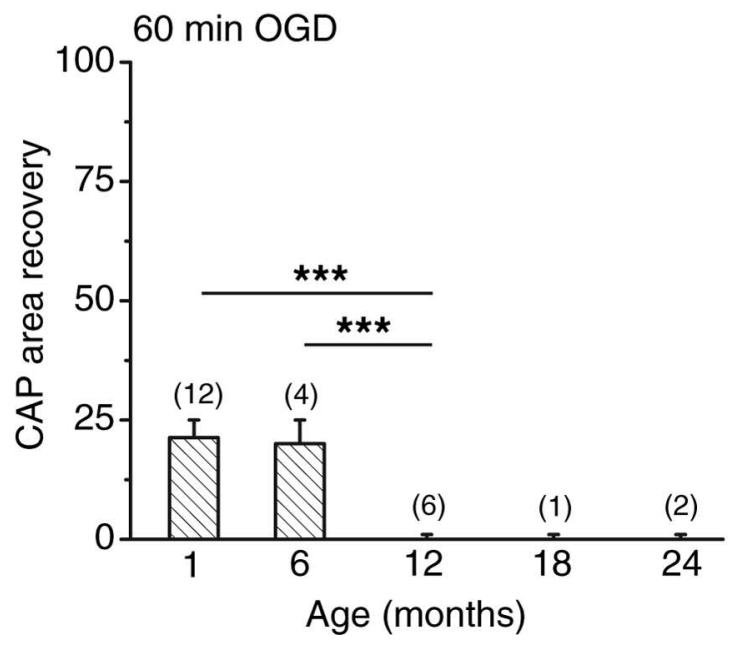

Figure 2. Similar durations of $O G D$ cause a greater extent of irreversible functional injury in older WM. The extent of CAP area recovery was drastically reduced after $30(\boldsymbol{a}), 45(\boldsymbol{b})$, or $60 \mathrm{~min}$ (c) of 0 GD starting at ages 18,12 , and 12 months, respectively. ${ }^{*} p<0.05,{ }^{* *} p<0.01,{ }^{* * *} p<$ 0.0016 , one-way ANOVA. Error bars indicate SEM.

In general, the older the animals were, the greater was the OGDinduced injury (Fig. 2). It should be noted that the CAP area recovery remained stable after OGD, without any significant change over the next $6 \mathrm{~h}$ in each age group.

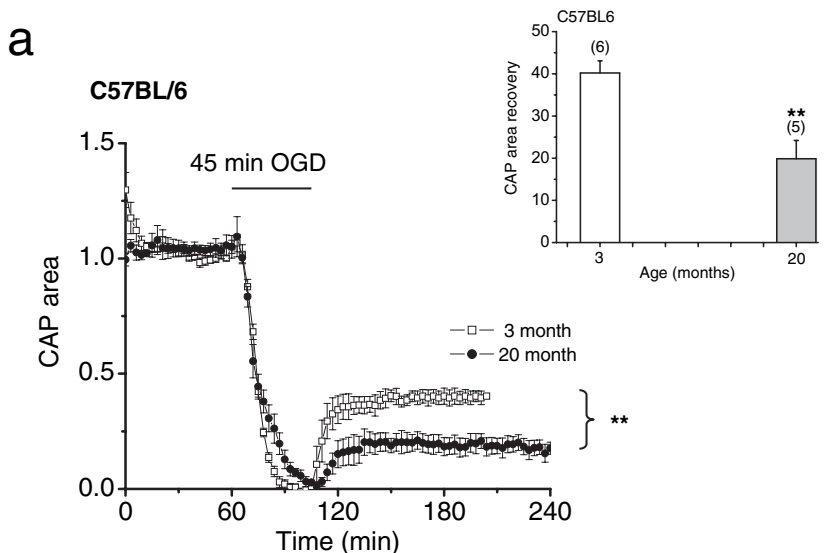

b

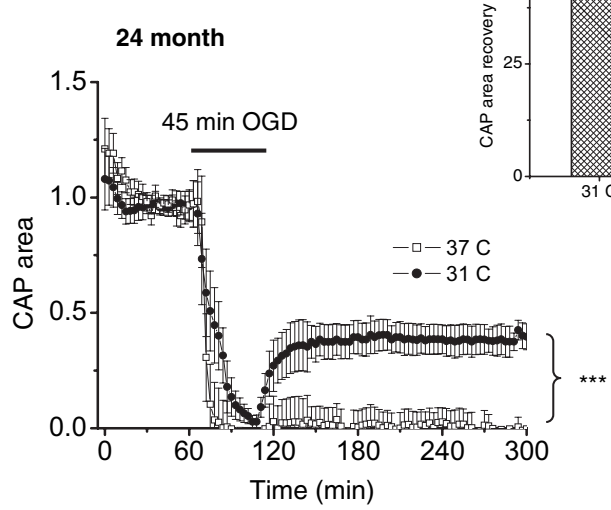

Figure 3. OGD-induced injury in older WM is temperature dependent and evident in mice of different strains. $\boldsymbol{a}$, The $45 \mathrm{~min} 0 \mathrm{GD}$ reduced CAP area recovery in 20-month-old compared with 3-month-old MONs obtained from C57BL/6 mice. ${ }^{* *} p=0.003$, Student's t test. $\boldsymbol{b}$, Lowering the temperature from 37 to $31^{\circ} \mathrm{C}$ dramatically restored the CAP area recovery in 24-month-old MONs after $45 \mathrm{~min}$ of $0 G \mathrm{D}$. The inset shows quantification of CAP area recovery after $45 \mathrm{~min}$ of $0 \mathrm{GD}$ at $37^{\circ} \mathrm{C}(0.0 \pm 5.6 \% ; n=6)$ or at $31^{\circ} \mathrm{C}\left(39.6 \pm 5.6 \% ; n=7 ;{ }^{* * *} p=0.0004\right.$, Student's $t$ test). Error bars indicate SEM.

The greater OGD-induced injury seen in older animals using electrophysiological analysis (i.e., CAP area) was confirmed in a limited series of morphological studies (supplemental Fig. 2, available at www.jneurosci.org as supplemental material). The oligodendrocyte and axon neurofilament loss were both much greater after OGD (45 min) in 12-month-old compared with 1-month-old MONs (supplemental Fig. 2, available at www. jneurosci.org as supplemental material).

To ensure that this age-related increase in vulnerability to OGD-induced injury was not a strain-specific effect, similar experiments were done on another strain. MONs from 3- or 20month-old C57BL/6 mice were exposed to 45 min OGD (Fig. $3 a$ ). As seen with the SW mice, the CAP recovery was significantly decreased after 45 min of OGD in MONs from 20-month-old $(19.9 \pm 4.3 \% ; n=5)$ compared with 3-month-old C57BL/6 mice (40.2 $\pm 2.9 ; n=6 ; p=0.003)$, establishing that the increased intrinsic vulnerability of WM to ischemia is present across strains.

The extent of WM injury after identical insults is highly dependent on temperature (Stys et al., 1992; Li et al., 2000). Low temperature strongly decreased the extent of OGD-induced injury in older animals (Fig. 3b). The amount of CAP recovery was significantly higher when $45 \mathrm{~min}$ OGD was imposed at $31^{\circ} \mathrm{C}$ 
compared with $37^{\circ} \mathrm{C}(39.6 \pm 5.6 \%, n=7$, compared with $0.0 \pm$ $5.6 \%, n=6 ; p=0.0004)$.

OGD-induced injury in older WM is not prevented by removal of extracellular $\mathrm{Ca}^{2+}$

The OGD-induced WM injury in MONs is strongly dependent on the presence of extracellular $\mathrm{Ca}^{2+}$ during the insult period (Stys and Lopachin, 1998; Tekkök et al., 2007). Whereas 60 min OGD continued to produce immediate loss of excitability in the absence of extracellular $\mathrm{Ca}^{2+}$, CAP area recovery in 1-month-old MONs was greatly improved $(95.7 \pm 4.3 \% ; n=6)$ compared with CAP recovery when OGD is applied in the presence of $\mathrm{Ca}^{2+}$ (Fig. 4a). We performed experiments to test whether the damaging effects of OGD in older MONs shared a similar critical dependency on extracellular $\mathrm{Ca}^{2+}$. Curiously, CAP recovery in older animals did not benefit from application of OGD (30 or $45 \mathrm{~min}$ ) in $\mathrm{Ca}^{2+}$-free ACSF (Fig. 4b,c). In fact, OGD applied in $\mathrm{Ca}^{2+}$-free ACSF resulted in significantly worse recovery (after a short period of transient improvement). The application of $\mathrm{Ca}^{2+}$-free ACSF had no effect on baseline CAP responses in any age group, even for periods up to $90 \mathrm{~min}$ (data not shown).

The WM in young adult animals is protected from OGDinduced injury by blockade of $\mathrm{Ca}^{2+}$ influx secondary to reverse operation of the NCX (Fig. $5 a$ ). The lack of protection by $\mathrm{Ca}^{2+}$ free ACSF suggested that $\mathrm{Ca}^{2+}$ influx might not be fundamental to WM ischemic injury in older animals. Indeed, blockade of reverse operation of the NCX with KB-R $7943(10 \mu \mathrm{M})$ did not prevent OGD-induced injury in WM from 12-month-old animals (Fig. 5b). In 12-month-old MONs, KB-R 7943 did prevent complete loss of CAPs during OGD and also transiently improved recovery, but the benefit rapidly disappeared.

\section{AMPA/kainate receptors mediate OGD-induced injury in older WM}

Overactivation of AMPA/kainate receptors plays a major role in ischemic WM injury (Agrawal and Fehlings, 1997; Matute et al., 1997; McDonald et al., 1998; Tekkök and Goldberg, 2001), including in 1- to 2-month-old MONs (Tekkök et al., 2007). To assess the contribution of AMPA/kainate receptor activation on WM injury in older animals, NBQX, a broad-spectrum AMPA/ kainate receptor blocker, was tested in 12- and 24-month-old animals. Application of $30 \mu \mathrm{M}$ NBQX prevented complete loss of CAP area during OGD and led to dramatically improved CAP area recovery compared with recovery in normal ACSF both in 12-month-old MONs (NBQX recovery, 72.4 $\pm 6.3, n=7$ after 45 min OGD, $p<0.0001 ; 65.9 \pm 6.2 \%, n=4, p<0.0001$ after 60 min OGD) and 24-month-old MONs (51.0 $\pm 6.4 \% ; n=4 ; p=$ 0.0001 ) (see Fig. $7 a-c$ ). Blockade of AMPA/kainate type glutamate receptors, therefore, protected WM function during and after OGD in every age group, but the effects were clearly magnified in 12- and 24-month-old animals (Fig. 6d).

\section{NMDA receptors do not protect against OGD-induced injury in older WM}

Recent studies report that functional NMDA receptors located on oligodendrocyte processes (Karadottir et al., 2005) mediate $\mathrm{Ca}^{2+}$ influx into myelin (Micu et al., 2006) and rapid $\mathrm{Ca}^{2+}$ dependent detachment and disintegration of oligodendroglial processes during ischemia (Salter and Fern, 2005). Previous studies on WM from young adult animals have failed to detect any benefit of NMDA receptor blockade on WM injury because of anoxia (Ransom et al., 1990), ischemia (Yam et al., 2000; Tekkök and Goldberg, 2001; Tekkök et al., 2007), or glutamate applica- a

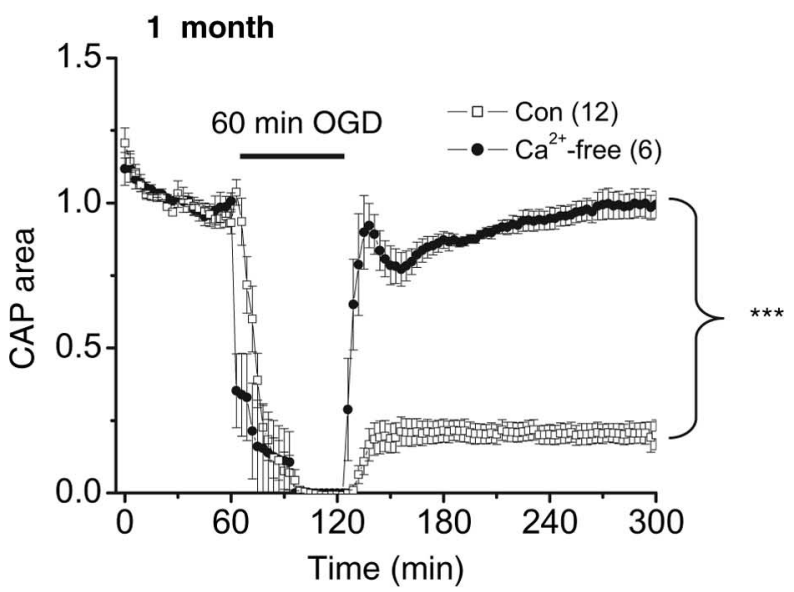

b
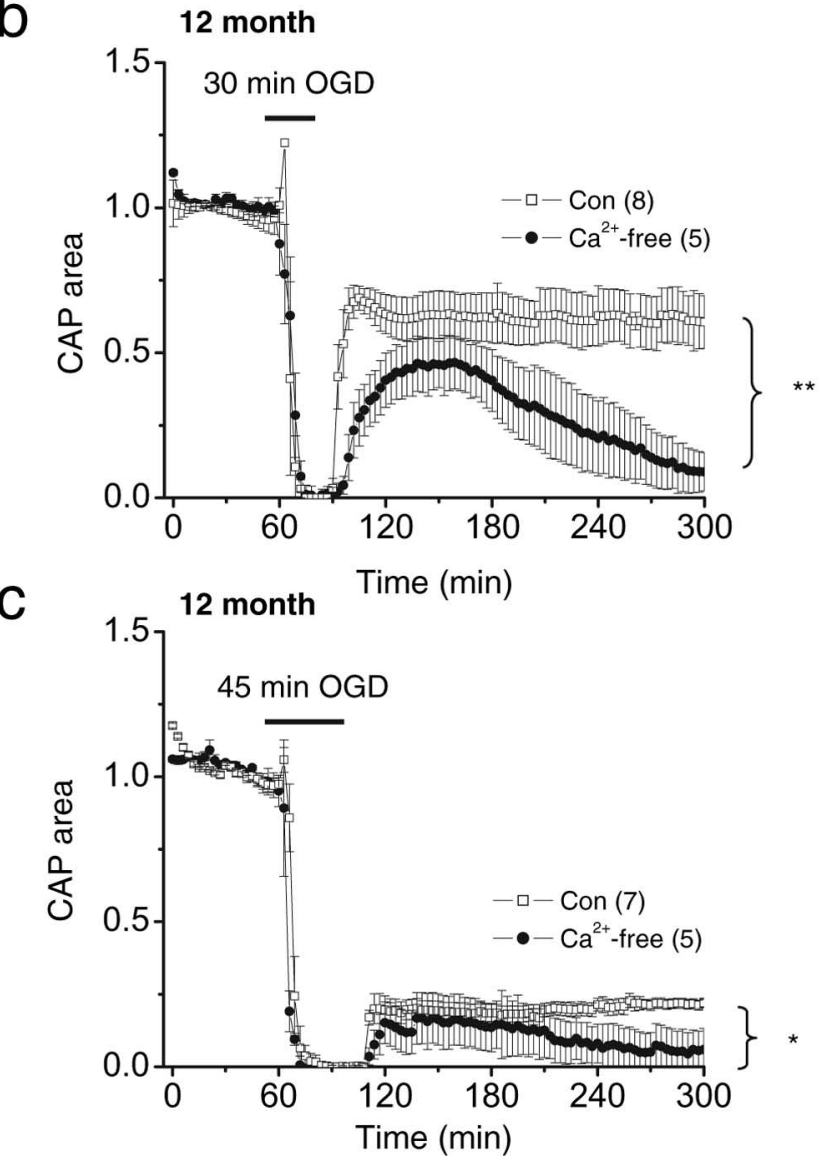

Figure 4. OGD-induced injury in older WM is $\mathrm{Ca}^{2+}$ independent. MONs were exposed to 0 GD in normal ACSF (containing $2 \mathrm{~mm} \mathrm{Ca}^{2+}$ ) or in ACSF with no $\mathrm{Ca}^{2+}$ (plus $200 \mu \mathrm{m}$ EGTA and $4 \mathrm{~mm} \mathrm{Mg}^{2+}$ ). Superfusion conditions were maintained starting 30 min before, during, and 30 min after OGD. $\boldsymbol{a}$, Pretreatment with $\mathrm{Ca}^{2+}{ }_{\text {- }}$ free ACSF offered nearly complete recovery from 60 min OGD injury in 1-month-old MONs $(95.6 \pm 4.3 \% ; n=6)$. The CAP area recovery in 12month-old MONs failed to show comparable recovery after $30 \mathrm{~min}(\boldsymbol{b})$ or $45 \mathrm{~min}$ of OGD. Reproduced from Tekkök et al. (2007). c, Under identical conditions. The stability of the CAP area recovery after $\mathrm{OGD}$ in 12-month-old MONs dropped below recovery levels in $\mathrm{Ca}^{2+}$ containing ACSF (with $\mathrm{Ca}^{2+}, 60.5 \pm 9 \%$, without $\mathrm{Ca}^{2+}, 8.9 \pm 6.5 \%$ after 30 min of $0 \mathrm{GD}$; with $\mathrm{Ca}^{2+}$, $21.7 \pm 1.8 \%$, without $\mathrm{Ca}^{2+}, 5.9 \pm 6.8 \%$ after 45 min of $\left.0 \mathrm{GD}\right) .{ }^{*} p<0.05,{ }^{* *} p<0.002$, ${ }^{* * *} p<0.0001$, Student's $t$ test. Error bars indicate SEM.

tion (Li et al., 1999). We confirmed that the NR1 functional subunit was detected in MONs at each age group (Fig. $7 d$ ), including in 12-month-old MONs. Application of the NMDA receptor glycine binding site blocker, 7-CKA (50 $\mu \mathrm{M})$, had no ap- 
preciable effect on OGD-induced loss of excitability, but significantly worsened recovery from this insult (Fig. 7a-c) $(58.6 \pm$ $5.5 \%$ in ACSF vs $6.8 \pm 3.1 \%$ in 7 -CKA; $p<$ 0.001 after $30 \mathrm{~min}$ OGD). DL-AP5 (200 $\mu \mathrm{M})$, a potent selective blocker of NMDA receptors, confirmed these results. In the presence of DL-AP5, the degree of CAP recovery was diminished after $30 \mathrm{~min}$ of $\operatorname{OGD}(9.8 \pm 2.6 \% ; n=4 ; p=0.0001)$. The effect of NMDA receptor blockade, therefore, was reminiscent of the effect of $\mathrm{Ca}^{2+}$ free solution in that both of these conditions worsened the CAP recovery after OGD in aging WM (Fig. 4).

\section{Glutamate release during OGD was enhanced in older WM and correlated with glutamate transporter upregulation}

Glutamate, after a 20-30 min delay, is directly released from $\mathrm{MON}$ during OGD because of the reversal of $\mathrm{Na}^{+}$-dependent glutamate transport (Tekkök et al., 2007). A plausible explanation is that OGD dissipates the transmembrane $\mathrm{Na}^{+}$gradient in astrocytes (Rose and Ransom, 1996), leading to reverse exchange and glutamate release (Longuemare et al., 1999). The GLT1 glutamate transporter is exclusively expressed in astrocytes (Danbolt, 2001). As expected, astrocytes in the MON expressed the greatest density of these transporters (see Fig. 9b). In 12- and 24-monthold MONs, DL-TBOA $(200 \mu \mathrm{M})$, a powerful competitive $\mathrm{Na}^{+}$-dependent glutamate transporter blocker, potently improved the CAP area recovery after 45 or $60 \mathrm{~min}$ of OGD (Fig. $8 a-d$ ). When the degree of TBOA protection from ischemic WM injury is compared among animals of different ages, it is evident that it conveyed protection at all ages. It was also clear that the degree of protection was greater in older animals. For instance, after $45 \mathrm{~min}$ OGD, the CAP recovery in 12-month-old MONs with TBOA was improved from $21.7 \pm 2.7$ to $65.2 \pm 2.7 \%$ whereas in 24 month-old MONs the improvement was from $0.0 \pm 5.6$ to $70.2 \pm 0.8 \%$ (Fig. $7 b-d$ ). DHKA $(200 \mu \mathrm{M})$, a specific blocker of GLT1, also improved CAP recovery after $60 \mathrm{~min}$ OGD, and this effect was much greater in 12-month-old compared with 1 -month-old animals $(20.5 \pm 5.1$ to $39.4 \pm 6.6 \%, p=0.04 ; 0 \pm 1$ to $57.2 \pm$ $7.2 \%, p<0.0001$, respectively). Results from MONs pretreated with NBQX mirrored this relationship: after 45 min OGD, the improvement in 24-month-old MONs was greater compared with 12-month-old MONs (Fig. 6d).

These results suggested greater excitotoxicity in older animals (i.e., $\geq 12$ months) compared with younger ones (i.e., $\sim 1$ month
a
1 month
b
12 month
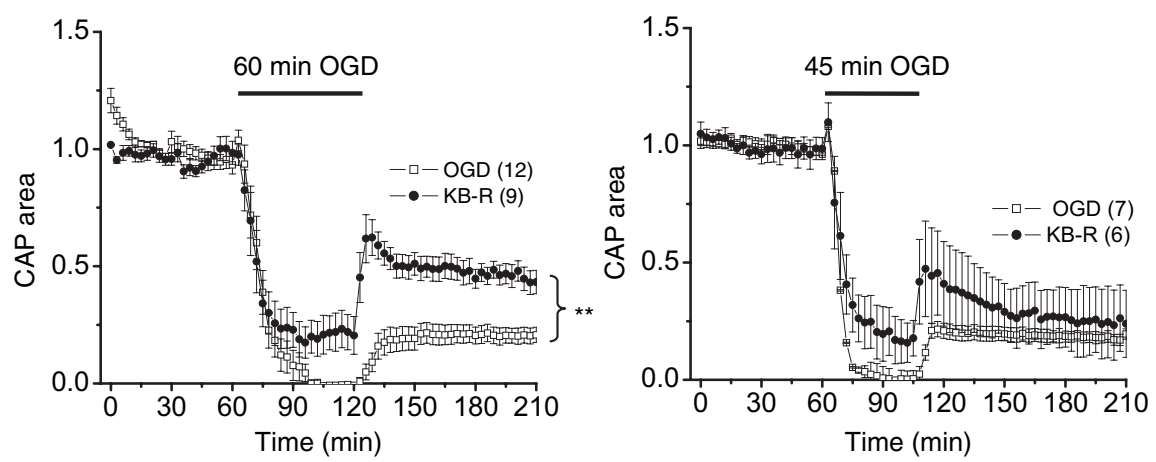

Figure 5. Blockade of the reversal of NCX does not reduce OGD-induced injury in WM from older animals. $\boldsymbol{a}, \mathrm{KB}-\mathrm{R}(10 \mu \mathrm{m})$, a specific blocker of the reversal of NCX, reduced CAP loss during OGD and substantially improved CAP area recovery after $60 \mathrm{~min}$ of OGD (43.3 $\pm 6.9 \%)$ in 1-month-old MONs. $\boldsymbol{b}$, KB-R prevented complete loss of the CAPs during OGD but did not improve recovery after 45 min of OGD in 12-month-old MONs $(23.1 \pm 14.8 \%) .{ }^{* *} p<0.008$, Student's $t$ test. Error bars indicate SEM. a 12 month
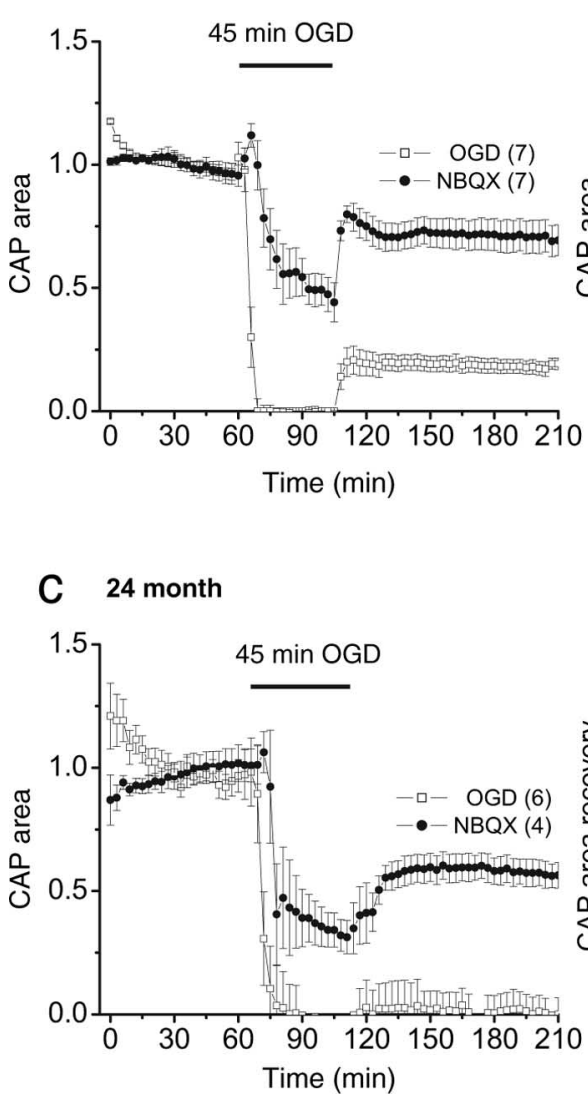

Figure 6. Blockade of AMPA/kainate receptors reduces OGD-induced injury in WM from all ages. Application of NBQX (30 $\mu \mathrm{M})$ reduced CAP loss during $0 G D$ and substantially improved CAP area recovery in 12-month-old MONs after $45 \mathrm{~min}(71.2 \pm 6.8 \%)$ $(\boldsymbol{a}), 60 \mathrm{~min}(63.5 \pm 6.9 \%)(\boldsymbol{b})$, and $45 \mathrm{~min}$ of OGD in $24-$ month-old MONs $(70.9 \pm 5.5 \%)$ (c). $\boldsymbol{d}$, Quantification of CAP area recovery after 45 or 60 min of $O G D$ in MONs pretreated with NBQX indicated comparable protection of WM function independent of age or duration of $0 G D$. ${ }^{* * *} p<0.0001$, two-way ANOVA. Error bars indicate SEM.
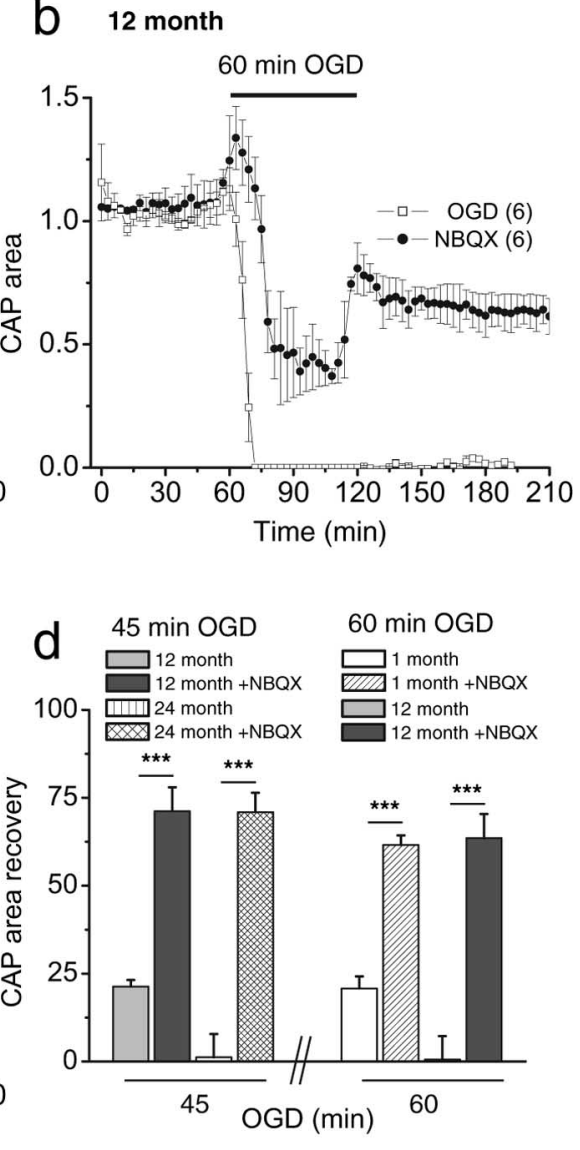

of age). We directly measured glutamate release from MONs during ischemia using quantitative HPLC to assess this crucial step in the excitotoxic cascade. Using a pair of MONs, baseline glutamate release levels at $37^{\circ} \mathrm{C}$ were determined for 20 min before OGD by sampling perfusion solution passed over the nerves 
a 12 month

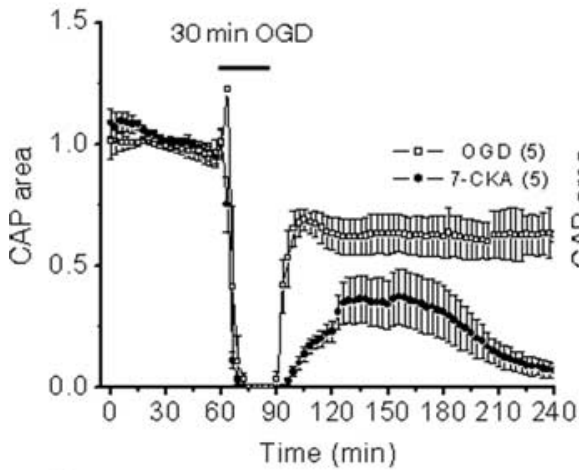

C

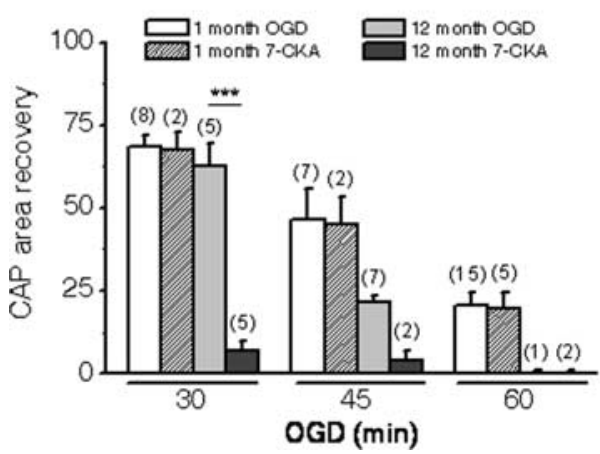

Figure 7. Blockade of NMDA receptors does not reduce OGD-induced injury in WM from older animals. The NMDA receptor glycine binding site blocker, 7-CKA $(50 \mu \mathrm{m})$, did not improve CAP area recovery after $30 \mathrm{~min}(\boldsymbol{a})$ or $45 \mathrm{~min}(\boldsymbol{b})$ of OGD in 12-month-old MONs. NMDA receptor blockade caused delayed loss of CAP area after OGD only in 12-month-old MONs. c, Quantification of CAP area recovery after 30,45, or $60 \mathrm{~min}$ of $0 \mathrm{GD}$ in the 1-month-old MONs pretreated with 7-CKA neither improved nor hindered recovery. In 12-month-old MONs, the CAP area recovered less in 7-CKA compared with ACSF only. Error bars indicate SEM. $\boldsymbol{d}$, NMDA receptors (red) were expressed in all age groups and mostly on glial cell bodies (blue). ${ }^{* * *} p<0.001$, two-way ANOVA. Scale bar, $10 \mu \mathrm{m}$.

every 2 min (Tekkök et al., 2007). For comparison, all glutamate release data were normalized to the average control release levels, which were in the range of $4-6 \mathrm{~nm}(n=14)$ (data not shown). Initially during OGD, glutamate release remained stable at the baseline level for at least $20 \mathrm{~min}$ for all MONs (Fig. 9a). As previously reported (Tekkök et al., 2007), in 1-month-old MONs glutamate release steadily increased starting at $\sim 30$ min of OGD and reached maximal levels that were fourfold to fivefold higher compared with basal levels (i.e., $\sim 20-30 \mathrm{nmol} / \mathrm{L}$ ). On return to control ACSF, glutamate levels in 1-month-old MONs declined rapidly toward baseline within $20 \mathrm{~min}$. Notably, in 12-month-old MONs, glutamate release was initiated earlier during OGD, beginning at $\sim 20 \mathrm{~min}$ OGD, and the amount of glutamate release was higher at every time point measured. It must be recognized, of course, that glutamate is only detected in these experiments after it has escaped from the extracellular space of WM, which imposes a significant diffusion barrier, and commingles and is diluted by bath solution. The results were reliable and robust, and clearly showed that OGD caused earlier and greater glutamate release in older MONs. This finding correlated well with the increased ischemic injury seen in older animals and the impressive protection afforded by NBQX and TBOA in older animals.

We tested the hypothesis that the increase in glutamate release seen during OGD in 12-month-old compared with 1-month-old MONs was related to greater expression of glutamate transporter in older animals. The distribution and expression of GLT1 was investigated using confocal imaging and Western blotting. Immunolabeling of GLT1 demonstrated a twofold $(188.6 \pm 18.45 \% ; n=16)$ increase in intensity in 12-month-old compared with 1-month-old MONs (Fig. 9b,c). Western blots confirmed this observation. There was a twofold $(211.8 \pm 45.1 \% ; n=$ 6) increase in GLT1 protein expression between 1- and 12-month-old MONs (Fig. 9c). The increase in GLT1 expression may be specific to older WM because GLT1 labeling (data not shown) and protein levels (Fig. 9c) remained unchanged in the hippocampus at these two ages.

In 1-month-old MONs, GLT1 and GFAP expression showed substantial colabeling, suggesting that GLT1 was located principally on MON astrocytes (Fig. 9b, merged). Despite the fact that the orientation of GFAP $(+)$ processes changed from a transverse (1 month) to a more longitudinal orientation (12 months) (Fig. 9b), aging did not alter GFAP expression levels in WM or GM (Fig. 9c). However, GLT1 expression was clearly increased in 12month-old compared with 1-month-old MON but not in hippocampus (Fig. 9b,c). Although the majority of GLT1 immunoreactivity in 12-month-old animals remained colocalized to GFAP (i.e., on astrocytes), some appeared to fall outside GFAP profiles (Fig. 9b, merged). Even so, this "apparent" GFAP-independent GLT1 staining was arrayed in a linear manner, like the GFAP staining, perhaps suggesting that it was in astrocyte processes that stained weakly or negatively for GFAP or on some other WM components. This expansion of $\mathrm{Na}^{+}$-glutamate transporter expression in older WM could help explain the greater levels of glutamate release and the increased vulnerability of aging WM to ischemic injury.

\section{Discussion}

We directly tested, and confirmed, the hypothesis that WM from older adult animals was more susceptible to ischemic injury than WM from younger adults. An additional key finding was that the mechanisms responsible for irreversible WM ischemic injury change as a function of age. These novel observations have several important clinical implications. Stroke occurs in the elderly, and yet there has been virtually no appreciation that brain tissue in the aged is intrinsically more sensitive to ischemic damage. Our study establishes this principle for CNS WM, which is typically involved in human stroke. In addition, the cellular pathophysiology of stroke injury changes as a function of age, implying that treatment strategies derived from experimental work on young adults may be ineffective in the clinically relevant population. Finally, the well known tendency for equivalent brain insults to produce less damage in young adults compared with older adults (Ay et al., 2005) may have its first clear scientific explanation. The implication is that treatment strategies for brain insults like isch- 
emia must be optimized by taking into consideration age-related differences in pathophysiology.

\section{Axon function in aging WM is more susceptible to ischemia}

Ischemic damage on WM excitability was assessed by monitoring the supramaximal CAP area. Loss of the CAP area because of ischemia correlates with axon and oligodendrocyte loss and myelin damage (Tekkök and Goldberg, 2001; Tekkök et al., 2007). The severity of injury from the same insult was greater in WM from older animals (12 months) (Fig. 1), and this effect was graded; that is to say, 12-, 18-, and 24-month-old animals faired progressively worse with the same period of ischemia (Fig. 2). This effect of aging on WM vulnerability was apparent in two different strains of mice suggesting that this is a general feature of aging WM (Fig. $3 a$ ).

Several known age-related changes might contribute to this heightened ischemic vulnerability in older WM. The ability to maintain transmembrane ion gradients may be compromised in older animals because of declines in $\mathrm{Na}^{+} / \mathrm{K}^{+}$ ATPase activity (Scavone et al., 2005). This enzyme is primarily responsible for maintaining low intracellular $\mathrm{Na}^{+}$concentrations that permit neural signaling and underpin a host of other transport processes. Ion transport accounts for about one-half of all ATP utilization and $\mathrm{Na}^{+} / \mathrm{K}^{+}$ATPase activity alone is responsible for the majority of this consumption (Erecinska and Silver, 1994). Moreover, this transporter acts to rapidly restore the transmembrane $\mathrm{Na}^{+}$ gradient when this is degraded by energy deprivation. A loss of reserve in the activity of this key enzyme with advanced age is a plausible contributor to heightened WM injury susceptibility. Tissue transiently challenged with energy deprivation would be slower to restore normal ion gradients, permitting pathological processes related to ion derangement to operate for longer periods, producing more injury. Mitochondrial function also appears to decline in older animals presumably causing reduced ATP production. This has been demonstrated in cardiac (Lesnefsky et al., 2001), liver (Selzner et al., 2007), and brain (Toescu, 2005) cells. The disadvantages of compromised ATP levels in older animals would be similar to those described above for diminished $\mathrm{Na}^{+} / \mathrm{K}^{+}$ATPase activity. This was indeed suggested by better recovery of WM function in older animals when OGD was imposed at lower temperature (Fig. $3 b$ ). There is also evidence that free radical generation is augmented as a function of advanced age. This is a potentially valuable injury pathway to evaluate in future studies on age-related vulnerability (Droge and Schipper, 2007).
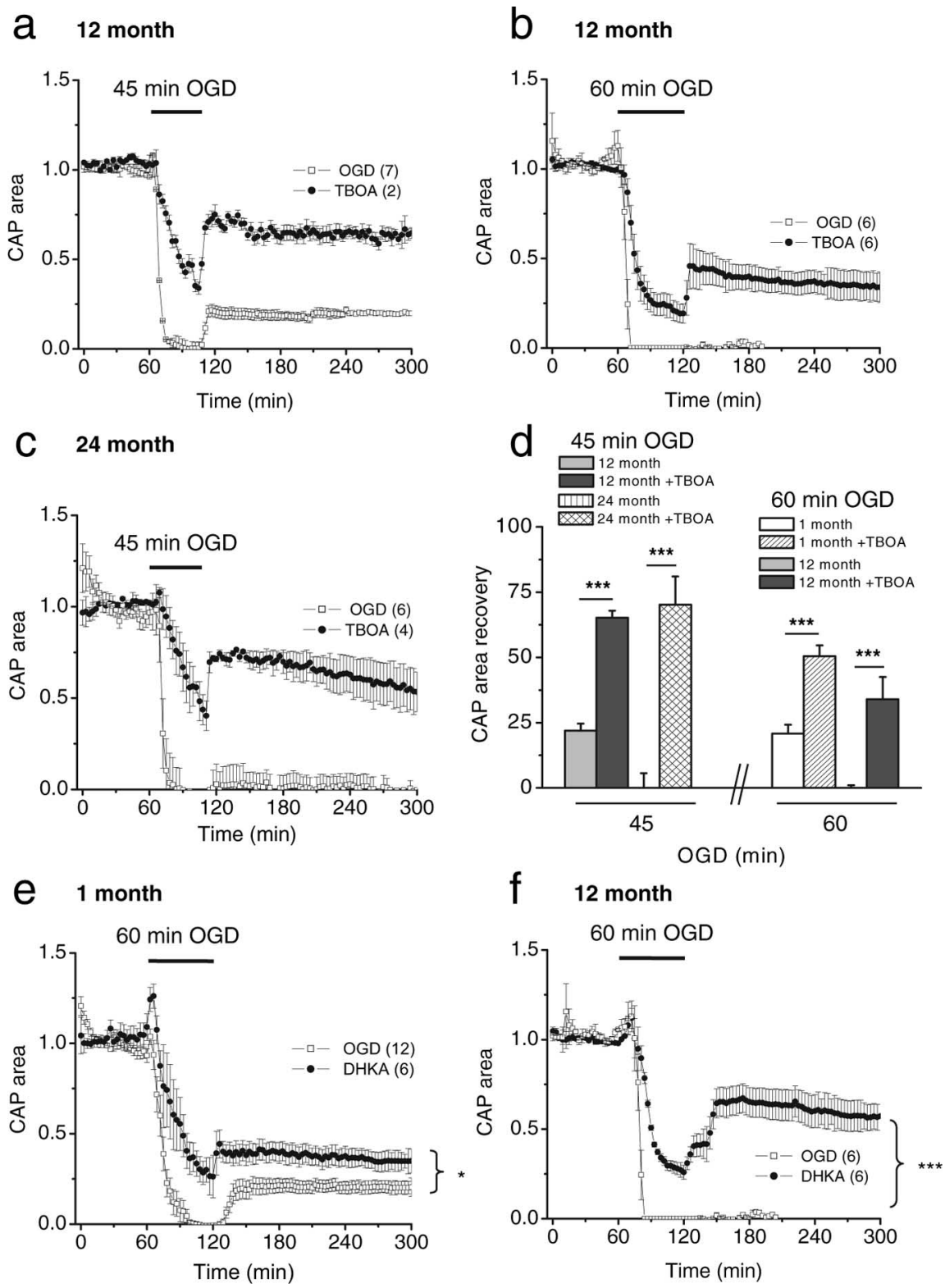

Figure 8. Blockade of the $\mathrm{Na}^{+}$-dependent glutamate transporters reduces $0 \mathrm{GD}$-induced injury in WM from all ages. The potent and competitive blocker of $\mathrm{Na}^{+}$-dependent glutamate transport, DL-TBOA (200 $\left.\mu \mathrm{M}\right)$, effectively improved the CAP area recovery after $45 \mathrm{~min}(\boldsymbol{a})$ or $60 \mathrm{~min}(\boldsymbol{b})$ OGD in 12-month-old MONs and $45 \mathrm{~min}$ OGD in 24-month-old MONs (c). d, Quantification of CAP area recovery after pretreatment with DL-TBOA revealed comparable protection of WM function, independent of age or duration of OGD. ${ }^{* * *} p<0.001$, two-way ANOVA. The selective blocker of $\mathrm{Na}^{+}$-dependent glutamate transporter GLT1, DHKA $(200 \mu \mathrm{M})$, improved the CAP area recovery after $60 \mathrm{~min}$ OGD in 1-month-old $(20.5 \pm 5.1, n=12 ; \mathrm{vs} 39.4 \pm 6.6, n=6)(\boldsymbol{e})$ and 12 -month-old MONs $(0 \pm 1, n=6 ;$ vs $57.2 \pm 7.2, n=6)(\boldsymbol{f}){ }^{*} p=0.04,{ }^{* * *} p<0.0001$, Student's t test. Error bars indicate SEM.

\section{AMPA/kainate but not NMDA receptors mediate excitotoxic injury during ischemia in older WM}

WM ischemic injury involves AMPA and kainate glutamate receptor activation; consequently, nonspecific glutamate receptor blockade is highly protective (Agrawal and Fehlings, 1997; Li et al., 1999; Li and Stys, 2000; Tekkök and Goldberg, 2001; Tekkök et al., 2005, 2007). Functional AMPA and kainate receptors are expressed on oligodendrocytes and the myelin they generate (Gallo and Ghiani, 2000; Li and Stys, 2000). In young animals, glutamate released during OGD activates $\mathrm{Ca}^{2+}$ permeable receptors (Sanchez-Gomez and Matute, 1999) and mediates oligodendrocyte death and axon disruption. In addition, axon injury may proceed independently in a $\mathrm{Ca}^{2+}$-dependent manner (Tekkök et 
a

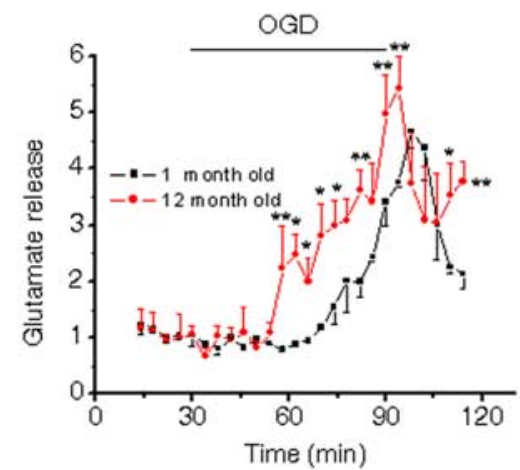

b
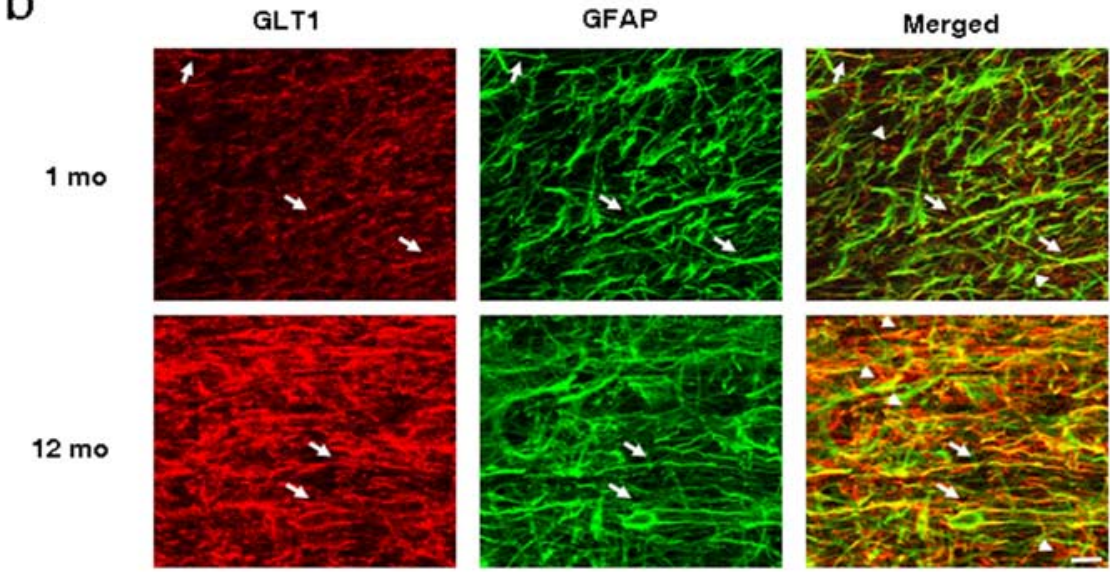

C
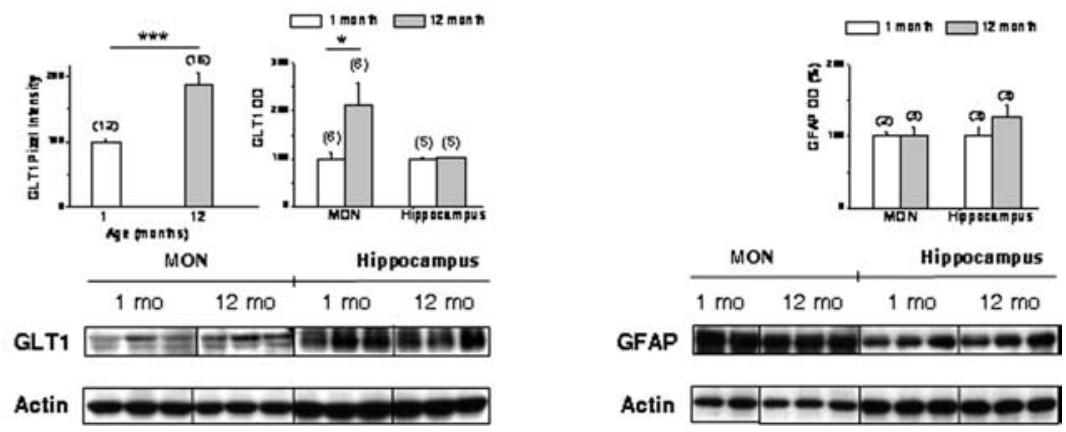

Figure 9. Increases in GLT1 expression in older WM is correlated with increased release of glutamate during OGD. $\boldsymbol{a}$, Baseline glutamate release in 1- or 12-month-old MONs was low and remained stable under control conditions. Glutamate release steadily increased starting at $30 \mathrm{~min}$ after the onset of $0 \mathrm{GD}$ and reached a level fivefold greater than baseline in 1-month-old MONs ( $n=$ 7). Under identical conditions, glutamate release started $20 \mathrm{~min}$ after the onset of $O G D$ and was significantly higher at every time point during $O G D$ in 12-month-old compared with 1-month-old MONs $(n=7)$. Note the relatively sustained glutamate levels after the conclusion of OGD in 12-month-old MONs. $\boldsymbol{b}$, GLT1 (red) and GFAP (green) labeling indicated that GLT1 was mainly expressed on astrocytes (merged) in 1-month-old MONs. c, There was a twofold increase in GLT1 labeling pixel intensity (188.6 \pm 18.5\%) and expression (211.8 $\pm 45.1 \%$ ) with age in MONs but not in the hippocampus. The pattern of GFAP expression in MONs changed with age but without increase either in MONs $(102.0 \pm 9.9 ; n=3 ; p=0.8906)$ or in hippocampus $(127.9 \pm 14.3 ; n=$ $3 ; p=0.2068) .{ }^{*} p<0.05,{ }^{* *} p<0.005,{ }^{* * *} p<0.001$, Student's $t$ test. The arrows indicate GLT1 and GFAP overlap; the arrowheads indicate GLT1 labeling on structures other than GFAP (+). Scale bar, $10 \mu \mathrm{m}$. Error bars indicate SEM.

al., 2007). Accordingly, injury is almost entirely prevented when OGD is administered in the absence of bath $\mathrm{Ca}^{2+}$ (Fern et al., 1995; Li et al., 2000; Tekkök and Goldberg, 2001; Wolf et al., 2001; Tekkök et al., 2007). In contrast, aging WM could not be protected from OGD in the absence of extracellular $\mathrm{Ca}^{2+}$, suggesting that $\mathrm{Ca}^{2+}$ influx did not mediate the injury despite the activation of AMPA/kainate receptors during OGD (Fig. 6). How, then, does activation of AMPA/kainate receptors mediate WM damage? It is possible that accumulation of intracellular $\mathrm{Na}^{+}$, mediated in part by AMPA/kainate receptors, might be the predominant toxic event in aging WM exposed to ischemia, perhaps because it induces lethal swelling (Rothman, 1985; Olney et al., 1986). Moreover, a rise in intracellular $\mathrm{Na}^{+}$promotes reversal of the $\mathrm{Na}^{+}$-dependent glutamate transporter, whose expression is upregulated (Fig. $9 b, c)$, resulting in greater glutamate efflux (Szatkowski et al., 1990; Longuemare and Swanson, 1995). An alternative possibility is that glutamate receptor activation in aging WM causes sufficient intracellular $\mathrm{Ca}^{2+}$ release to cause damage (Ouardouz et al., 2003). This, of course, could act in parallel to the pathophysiology driven by intracellular $\mathrm{Na}^{+}$ accumulation.

The NMDA receptors located on oligodendrocyte processes were recently shown to contribute to ischemic injury to these cells in rodents (Karadottir et al., 2005; Salter and Fern, 2005; Micu et al., 2006). In our previous studies on mature WM, blockade of NMDA receptors did not offer functional or histological protection against ischemia (Tekkök and Goldberg, 2001; Tekkök et al., 2007). We confirmed in the present study that the NR1 subunit of NMDA was expressed in MONs of all ages (Fig. 7d). Therefore, we carefully searched for involvement of NMDA receptors in OGD-induced injury in aging MONs. The NMDA receptor blockers, 7-CKA or DL-AP5, did not improve recovery or shape of the CAPs (Fig. 7a,b). These results support the principle that NMDA receptor antagonism does not provide effective protection against ischemia in young or older WM (Fig. 7d). Moreover, blockade of these receptors caused a slow and persistent loss in the CAP area, implying a delayed injury process during reperfusion (Fig. 7a,b). The clinical implications of this worsening of ischemic WM injury with NMDA antagonism are important to note.

\section{Increased GLT1 expression and early release of glutamate in older WM}

An important finding of this study was that OGD-induced glutamate release occurred earlier and was greater in magnitude in older compared with young adult animals (Fig. $9 a)$. This, of course, caused excitotoxic events to ensue earlier and more vigorously in aging animals. Obviously, this is an appealing explanation for the greater level of ischemic damage seen in aging animals. The probable reason for glutamate release during OGD is a loss of the transmembrane $\mathrm{Na}^{+}$ gradient leading to reverse $\mathrm{Na}^{+}$-dependent glutamate transport because of ATP depletion and failure of $\mathrm{Na}^{+}-\mathrm{K}^{+}$ATPase. The latter events would set the threshold for "when" glutamate release would be initiated during OGD. The amount of glutamate release, however, could be influenced by the density of transporter expression. It is, therefore, of great interest that expression of GLT1 was significantly and selectively upregulated in older animals (Fig. $9 b, c)$. 
Glutamate release was greatly reduced by blockade of $\mathrm{Na}^{+}$dependent glutamate transport in young WM (Tekkök et al., 2007). That TBOA protects aging WM indicates that glutamate release by reverse $\mathrm{Na}^{+}$-dependent glutamate transport was a common mechanism contributing to ischemic injury in WM of all ages (Fig. 8). The selective GLT1 blocker, DHKA, was more powerful than TBOA in protecting old WM, compared with young WM, supporting the hypothesis that the GLT1 transporter plays a more prominent role during ischemic injury with aging. These transporters are most robustly expressed on astrocytes in young WM but may extend to additional structures with aging (Fig. 9b). It is probable that astrocytes are the primary source of ischemic glutamate release in WM; however, it is not clear why astrocytes would release glutamate more rapidly in older animals unless ATP depletion occurs earlier or they are subject to more intense degradation of their transmembrane $\mathrm{Na}^{+}$gradient (see above).

\section{$\mathrm{Ca}^{2+}$-independent excitotoxicity in older WM}

Originally, we predicted that the removal of extracellular $\mathrm{Ca}^{2+}$ during OGD would ameliorate axon injury in older WM. However, this manipulation actually aggravated the injury (Fig. 4). This paradoxical observation was further confirmed in experiments averting $\mathrm{Ca}^{2+}$ influx by blockade of NMDA receptors (Fig. 7) (another route of $\mathrm{Ca}^{2+}$ entry), and by blockade of NCX reversal (Fig. 5). Although it is generally believed that excessive $\mathrm{Ca}^{2+}$ entry and the resultant cytosolic $\mathrm{Ca}^{2+}$ overload plays a central role in hypoxic injury, several in vitro studies on neurons have challenged this dogma (Goldberg and Choi, 1993). Our findings in aging MON diverge from previous findings in various WM preparations, including young MONs (Tekkök et al., 2007). It is possible that $\mathrm{Ca}^{2+}$ release from intracellular $\mathrm{Ca}^{2+}$ stores (ICS) during ischemia (Ouardouz et al., 2003) may become more critical in aging MONs. However, the exact relationship between transmembrane $\mathrm{Ca}^{2+}$ influx and cytosolic free $\mathrm{Ca}^{2+}$ concentration, and the role of ICS in aging WM have yet to be established.

In addition, the experiments interfering with $\mathrm{Ca}^{2+}$ entry unveiled a paradoxical loss of CAP during the reperfusion period. In $\mathrm{Ca}^{2+}$-free experiments, $\mathrm{Ca}^{2+}$ was replaced by equimolar concentrations of $\mathrm{Mg}^{2+}$ to rule out " $\mathrm{Ca}^{2+}$ paradox" (Chinopoulos et al., 2004). Moreover, in control experiments, exposing MONs to $\mathrm{Ca}^{2+}$-free ACSF for similar durations without OGD did not affect axon excitability in WM. Experiments in which $\mathrm{Ca}^{2+}$ entry via NMDA receptors, or the reverse operation of NCX, were blocked in the presence of normal extracellular $\mathrm{Ca}^{2+}$ levels also resulted in slow persistent loss of axon function during reperfusion (Figs. 5, 7). The importance of intracellular $\mathrm{Ca}^{2+}\left(\left[\mathrm{Ca}^{2+}\right]_{\mathrm{i}}\right)$ for cell survival is well documented. Levels that are too high can lead to necrosis, and levels that are too low can sometimes induce apoptosis. One possibility is that older animals have an altered balance such that reductions in $\left[\mathrm{Ca}^{2+}\right]_{\mathrm{i}}$ more readily induce delayed apoptotic injury. This idea would be the most economical but by no means the only explanation of our observations.

\section{References}

Agrawal SK, Fehlings MG (1996) Mechanisms of secondary injury to spinal cord axons in vitro: role of $\mathrm{Na}^{+}, \mathrm{Na}^{+}-\mathrm{K}^{+}$-ATPase, the $\mathrm{Na}^{+}-\mathrm{H}^{+}$exchanger, and the $\mathrm{Na}^{+}{ }_{-} \mathrm{Ca}^{2+}$ exchanger. J Neurosci 16:545-552.

Agrawal SK, Fehlings MG (1997) Role of NMDA and non-NMDA ionotropic glutamate receptors in traumatic spinal cord axonal injury. J Neurosci 17:1055-1063.

Ay H, Koroshetz WJ, Vangel M, Benner T, Melinosky C, Zhu M, Menezes N, Lopez CJ, Sorensen AG (2005) Conversion of ischemic brain tissue into infarction increases with age. Stroke 36:2632-2636.
Baltan S (2007) Mechanisms of ischemic injury in aging white matter. Paper presented at EuroGlia Meeting, London, UK, September.

Cavallotti C, Pacella E, Pescosolido N, Tranquilli-Leali FM, Feher J (2002) Age-related changes in the human optic nerve. Can J Ophthalmol 37:389-394.

Cavallotti C, Cavallotti D, Pescosolido N, Pacella E (2003) Age-related changes in rat optic nerve: morphological studies. Anat Histol Embryol 32:12-16.

Chinopoulos C, Gerencser AA, Doczi J, Fiskum G, Adam-Vizi V (2004) Inhibition of glutamate-induced delayed calcium deregulation by 2 -APB and $\mathrm{La}^{3+}$ in cultured cortical neurones. J Neurochem 91:471-483.

Cummins KL, Perkel DH, Dorfman LJ (1979) Nerve fiber conductionvelocity distributions. I. Estimation based on the single-fiber and compound action potentials. Electroencephalogr Clin Neurophysiol 46:634-646.

Danbolt NC (2001) Glutamate uptake. Prog Neurobiol 65:1-105.

Del Zoppo GJ (1995) Why do all drugs work in animals but none in stroke patients? 1. Drugs promoting cerebral blood flow. J Intern Med 237:79-88.

Del Zoppo GJ (1998) Clinical trials in acute stroke: why have they not been successful? Neurology 51:S59-S61.

Dirnagl U (2006) Bench to bedside: the quest for quality in experimental stroke research. J Cereb Blood Flow Metab 26:1465-1478.

Droge W, Schipper HM (2007) Oxidative stress and aberrant signaling in aging and cognitive decline. Aging Cell 6:361-370.

Erecinska M, Silver IA (1994) Ions and energy in mammalian brain. Prog Neurobiol 43:37-71.

Fern R, Ransom BR (1997) Ischemic injury of optic nerve axons: the nuts and bolts. Clin Neurosci 4:246-250.

Fern R, Ransom BR, Waxman SG (1995) Voltage-gated calcium channels in CNS white matter: role in anoxic injury. J Neurophysiol 74:369-377.

Follett PL, Rosenberg PA, Volpe JJ, Jensen FE (2000) NBQX attenuates excitotoxic injury in developing white matter. J Neurosci 20:9235-9241.

Foster RE, Connors BW, Waxman SG (1982) Rat optic nerve: electrophysiological, pharmacological and anatomical studies during development. Dev Brain Res 3:371-386.

Gallo V, Ghiani CA (2000) Glutamate receptors in glia: new cells, new inputs and new functions. Trends Pharmacol Sci 21:252-258.

Goldberg MP, Choi DW (1993) Combined oxygen and glucose deprivation in cortical cell culture: calcium-dependent and calcium-independent mechanisms of neuronal injury. J Neurosci 13:3510-3524.

Hinman JD, Abraham CR (2007) What's behind the decline? The role of white matter in brain aging. Neurochem Res 32:2023-2031.

Hinman JD, Peters A, Cabral H, Rosene DL, Hollander W, Rasband MN, Abraham CR (2006) Age-related molecular reorganization at the node of Ranvier. J Comp Neurol 495:351-362.

Karadottir R, Cavelier P, Bergersen LH, Attwell D (2005) NMDA receptors are expressed in oligodendrocytes and activated in ischaemia. Nature 438:1162-1166.

Lesnefsky EJ, Gudz TI, Migita CT, Ikeda-Saito M, Hassan MO, Turkaly PJ, Hoppel CL (2001) Ischemic injury to mitochondrial electron transport in the aging heart: damage to the iron-sulfur protein subunit of electron transport complex III. Arch Biochem Biophys 385:117-128.

Li S, Stys PK (2000) Mechanisms of ionotropic glutamate receptormediated excitotoxicity in isolated spinal cord white matter. J Neurosci 20:1190-1198.

Li S, Mealing GA, Morley P, Stys PK (1999) Novel injury mechanism in anoxia and trauma of spinal cord white matter: glutamate release via reverse $\mathrm{Na}^{+}$-dependent glutamate transport. J Neurosci 19:RC16(1-9).

Li S, Jiang Q, Stys PK (2000) Important role of reverse $\mathrm{Na}^{+}-\mathrm{Ca}^{2+}$ exchange in spinal cord white matter injury at physiological temperature. J Neurophysiol 84:1116-1119.

Longuemare MC, Swanson RA (1995) Excitatory amino acid release from astrocytes during energy failure by reversal of sodium-dependent uptake. J Neurosci Res 40:379-386.

Longuemare MC, Rose CR, Farrell K, Ransom BR, Waxman SG, Swanson RA (1999) $\mathrm{K}^{+}$-induced reversal of astrocyte glutamate uptake is limited by compensatory changes in intracellular $\mathrm{Na}^{+}$. Neuroscience 93:285-292.

Matute C, Sanchez-Gomez MV, Martinez-Millan L, Miledi R (1997) Glutamate receptor-mediated toxicity in optic nerve oligodendrocytes. Proc Natl Acad Sci USA 94:8830-8835.

McDonald JW, Althomsons SP, Hyrc KL, Choi DW, Goldberg MP (1998) 
Oligodendrocytes from forebrain are highly vulnerable to AMPA/kainate receptor-mediated excitotoxicity. Nat Med 4:291-297.

Micu I, Jiang Q, Coderre E, Ridsdale A, Zhang L, Woulfe J, Yin X, Trapp BD, McRory JE, Rehak R, Zamponi GW, Wang W, Stys PK (2006) NMDA receptors mediate calcium accumulation in myelin during chemical ischaemia. Nature 439:988-992.

O'Collins VE, Macleod MR, Donnan GA, Horky LL, van der Worp BH, Howells DW (2006) 1,026 experimental treatments in acute stroke. Ann Neurol 59:467-477.

Olney JW, Price MT, Samson L, Labruyere J (1986) The role of specific ions in glutamate neurotoxicity. Neurosci Lett 65:65-71.

Ouardouz M, Nikolaeva MA, Coderre E, Zamponi GW, McRory JE, Trapp BD, Yin X, Wang W, Woulfe J, Stys PK (2003) Depolarization-induced $\mathrm{Ca}^{2+}$ release in ischemic spinal cord white matter involves L-type $\mathrm{Ca}^{2+}$ channel activation of ryanodine receptors. Neuron 40:53-63.

Peters A, Sethares C (2002) Aging and the myelinated fibers in prefrontal cortex and corpus callosum of the monkey. J Comp Neurol 442:277-291.

Ransom BR, Philbin Jr DM (1992) Anoxia-induced extracellular ionic changes in CNS white matter: the role of glial cells. Can J Physiol Pharmacol 70:S181-S189.

Ransom BR, Waxman SG, Davis PK (1990) Anoxic injury of CNS white matter: protective effect of ketamine. Neurology 40:1399-1403.

Rose CR, Ransom BR (1996) Mechanisms of $\mathrm{H}^{+}$and $\mathrm{Na}^{+}$changes induced by glutamate, kainate, and D-aspartate in rat hippocampal astrocytes. J Neurosci 16:5393-5404.

Rothman SM (1985) The neurotoxicity of excitatory amino acids is produced by passive chloride influx. J Neurosci 5:1483-1489.

Salter MG, Fern R (2005) NMDA receptors are expressed in developing oligodendrocyte processes and mediate injury. Nature 438:1167-1171.

Sanchez-Gomez MV, Matute C (1999) AMPA and kainate receptors each mediate excitotoxicity in oligodendroglial cultures. Neurobiol Dis 6:475-485.

Sandell JH, Peters A (2002) Effects of age on the glial cells in the rhesus monkey optic nerve. J Comp Neurol 445:13-28.

Scavone C, Munhoz CD, Kawamoto EM, Glezer I, de Sa Lima L, Marcourakis T, Markus RP (2005) Age-related changes in cyclic GMP and PKGstimulated cerebellar Na,K-ATPase activity. Neurobiol Aging 26:907-916.

Schaller BJ (2007) Influence of age on stroke and preconditioning-induced ischemic tolerance in the brain. Exp Neurol 205:9-19.

Selzner M, Selzner N, Jochum W, Graf R, Clavien PA (2007) Increased isch- emic injury in old mouse liver: an ATP-dependent mechanism. Liver Transpl 13:382-390.

Stys PK (2004) White matter injury mechanisms. Curr Mol Med 4:113-130. Stys PK, Lopachin RM (1998) Mechanisms of calcium and sodium fluxes in anoxic myelinated central nervous system axons. Neuroscience 82:21-32.

Stys PK, Ransom BR, Waxman SG (1991) Compound action potential of nerve recorded by suction electrode: a theoretical and experimental analysis. Brain Res 546:18-32.

Stys PK, Waxman SG, Ransom BR (1992) Effects of temperature on evoked electrical activity and anoxic injury in CNS white matter. J Cereb Blood Flow Metab 12:977-986.

Szatkowski M, Barbour B, Attwell D (1990) Non-vesicular release of glutamate from glial cells by reversed electrogenic glutamate uptake. Nature 348:443-446.

Tekkök SB, Goldberg MP (2001) AMPA/kainate receptor activation mediates hypoxic oligodendrocyte death and axonal injury in cerebral white matter. J Neurosci 21:4237-4248.

Tekkök SB, Faddis BT, Goldberg MP (2005) AMPA/kainate receptors mediate axonal morphological disruption in hypoxic white matter. Neurosci Lett 382:275-279.

Tekkök SB, Ye Z, Ransom BR (2007) Excitotoxic mechanisms of ischemic injury in myelinated white matter. J Cereb Blood Flow Metab $27: 1540-1552$.

Toescu EC (2005) Normal brain ageing: models and mechanisms. Philos Trans R Soc Lond B Biol Sci 360:2347-2354.

Wolf JA, Stys PK, Lusardi T, Meaney D, Smith DH (2001) Traumatic axonal injury induces calcium influx modulated by tetrodotoxin-sensitive sodium channels. J Neurosci 21:1923-1930.

Wrathall JR, Teng YD, Choiniere D, Mundt DJ (1992) Evidence that local non-NMDA receptors contribute to functional deficits in contusive spinal cord injury. Brain Res 586:140-143.

Yam PS, Dunn LT, Graham DI, Dewar D, McCulloch J (2000) NMDA receptor blockade fails to alter axonal injury in focal cerebral ischemia. J Cereb Blood Flow Metab 20:772-779.

Ye ZC, Wyeth MS, Baltan-Tekkök S, Ransom BR (2003) Functional hemichannels in astrocytes: a novel mechanism of glutamate release. J Neurosci 23:3588-3596.

Zhang K, Sejnowski TJ (2000) A universal scaling law between gray matter and white matter of cerebral cortex. Proc Natl Acad Sci USA 97:56215626. 